\title{
PROPOSAL OF A NEW METHODOLOGY FOR THE IMPROVEMENT OF RISK ANALYSIS BASED ON ANALITYC NETWORK PROCESS
}

\author{
Alessandro Silvestri* \\ University of Cassino \\ Faculty of Engineering \\ Cassino, FR, ITALY \\ E-mail: silvestr@unicas.it \\ Fabio De Felice \\ University of Cassino \\ Faculty of Engineering \\ Cassino, FR, ITALY \\ E-mail: defelice@unicas.it \\ Antonella Petrillo \\ University of Cassino \\ Faculty of Engineering \\ Cassino, FR, ITALY \\ E-mail: a.petrillo@unicas.it \\ Ornella La Tegola ${ }^{(1)}$ \\ University of Cassino \\ Department of Law and Social Policy \\ Cassino, FR, ITALY \\ Email: lellalategola@yahoo.it
}

\begin{abstract}
The identification and choice of a suitable risk assessment model has been considered as a crucial issue for decades. In fact, the concern for safety in industrial activities, both inside the establishments and in the surroundings, has a long history. As a result, many laws and regulations apply. The use of risk assessment techniques is fairly widespread in policy and regulations. Current available risk analysis techniques are well adapted to industry needs since they were developed for its purpose. Risk assessment is a necessary step in the management of risk. Increasing safety is often difficult, especially when you have already obtained good of results, so the aim of our paper is the proposal of a new methodological approach called SIRA - Safety Improve Risk Assessment to assess the risk by defining an index called Total Risk Priority Number Index - TRPN. The index proposed is based on the Improved Risk Priority Number - IRPN and the Analytic Network Process - ANP, a Multi Criteria Decision Making - MCDM analysis tool.
\end{abstract}

Keywords: Risk Priority Number, Safety, Prevention, Protection

\footnotetext{
${ }^{*}$ Corresponding author

(1) Responsibility for the content of par. 2 should be given to Ornella La Tegola, Department of Law and Social Policy, University of Cassino, Italy. Email: lellalategola@yahoo.it
} 


\section{Introduction}

Safety routines such as inspections, audits and investigations produce a wide list of hazards and threats that are too numerous to be treated all at once. Decisions must be made which are the most urgent. This is often fulfilled by calculating Risk Priority Number - RPN (FMECA Method), which is furthermore the basis for risk ranking/prioritization helping managers to take decisions. RPN is calculated as a product between the probability of occurrence $(\mathrm{O})$, the severity $(\mathrm{S})$ of consequences and the probability of detection (D), RPN $=\mathrm{S} \times \mathrm{O} \times \mathrm{D}$. This is a widely used expression in industrial practices. For risk management, the technique has some advantages:

- $\quad$ Easy to understand and to use because of its simplicity;

- Well documented;

- Appropriate for training;

- $\quad$ Systemic and systematic for rapid decision taking.

Unfortunately the technique has some drawbacks in practice, in technical perspective and in the interpretation of the results as mentioned by Bowles (2003):

- $\quad$ The product of the RPN factors produces some holes in the scale;

- The RPN numbers are duplicated. In other words, different combination of ranking factors produce the same RPN and only 120 out of 1000 numbers generated are unique.

- There is a high sensitivity to small change in factors values caused by the effect of multiplication of the RPN factors.

This paper presents a new risk analysis methodology for complex systems. It provides a support to occupational safety and health team who want to take decisions in simplest possible way, mobilizing less time, human and financial resources.

\section{The legal obligation of risk assessment. Changes in regulations.}

On October 31, 1997 in Milan, there was a serious incident in the private health care facility named Orthopedic Institute "Galeazzi", in which it developed a fire that caused the death of the nurse and ten patients. Causally effective in identifying the conduct and criminal activity that led to the deaths of eleven people, the judges of the Supreme Criminal Court, sec. IV, in Case No. 4981 of 6 February 2004, motivated the condemnation of the employer and the Responsible of Prevention and Protection (among others) with the deficiencies found during risk assessment and the subsequent drafting of the document risk assessment. This judgment, as then declared by the European Court of Justice (also ECJ), cleared that the assessment of any risks to health and safety of workers is the most important tool for the prevention of those risks. The Court of Justice, in fact, in 15 November 2001, C-49/00, in the case of the EU Commission against the Italian Republic, declared that the Italian Republic had not properly transposed the Framework Directive 1989/391/CEE. Following that conviction, the Italian legislature amended Article 4 of d. lgs. 626/94 requiring the employer expressly to assess any risk to health and safety of workers as well as provide for new obligations in terms of professional qualifications and training and information for managers and service workers of protection and prevention. The subsequent evolution law occurring with the d. lgs. 81/08 confirms the willingness to recognize a legislative role to the documentation on safety. Back in Title I, in fact, the text deals only to redefine the risk assessment document by introducing new elements.

The first new that stresses the importance of risk assessment, is to set up a section of the legislative decree specific section (Section II - articles 28-30), while in the d. lgs. 626/94, standard rules on risk assessment were in the art. 4 containing the obligations of the employer, the manager and the provost.

Another modification concerns the mandatory content of the document for risk assessment. Article. 28 paragraph 2 of d. lgs. 81/08 states that it shall have a date certain and compulsory minimum content including the names of the RSPP and competent physician who collaborated in the writing and the RLS or RLST consulted. The legislative decree n. 81/08 does not specify which procedure must be followed in carrying out the risk assessment, thus leaving the responsibility of the employer and the technicians in charge by him to decide how to follow. 
They are, however, provided the reasons that force the employer to conduct a new risk assessment. As already stated in d. lgs. 626/94, in fact, the risk assessment may not be one-off but must be periodically revised under certain circumstances. As is known, d. lgs. 626/94 showed only changes in the production process, the d. lgs. 81/08 adds the changes of work relevant for the health and safety of workers, the evolution of technology, prevention and protection, significant injuries, as well as reporting on the health surveillance whose the need is demonstrated. It is believed that the latter provision should also apply in the case of the operational safety in temporary and mobile, as even (perhaps especially) in these areas can be envisaged significant changes in work organization such as, for example, the assignment of particular work to other firms and / or self-employed during construction.

In the Italian implementation of the Framework Directive 89/391/ECC, both the legislative decree of $19^{\text {th }}$ September 1994, n. 626 and the legislative decree $9^{\text {th }}$ April 2008 n. 81, as modified by the legislative decree $3^{\text {rd }}$ August 2009 n. 106, the worker is asked to cooperate actively in the risk assessment and the prevention of risks to health and safety in the workplace. According to art. 20 of the legislative decree $n$. $81 / 08$, in fact, workers are obliged to make correct use of machinery, other means of production, personal protective equipment and safety devices; to give warning of any work situation presenting a serious and immediate danger and of any shortcomings in the protection arrangements; to cooperate in fulfilling any requirement imposed for the protection of health and safety and in enabling the employer to ensure that the working environment and working conditions are safe and pose no risks. So, also the employees have the responsibility of the right implementation of the law.

$€$

\section{The proposed framework: SIRA Methodology}

Even if, the law does not specify which procedure must be followed in carrying out the risk assessment, the choice of a particular method by the employer and the technicians in charge by him, is fundamental, in order to drive the subsequent right actions of prevention and protection. In particular, in the riskmanagement process, quantification plays a central role (Silvestri, et al. 2004). It has therefore been necessary to standardize to a certain extent the metrics by which risk is expressed and the methodology, which is to be used to quantify risks and to manage these.

Risk has two dimensions, which have to be determined separately:

1. the extent of the consequences; and

2. the probability that the consequences will arrive.

From this point of view several methods have been developed to control the behaviour of safety or methods for safety management based on better behaviour critical to the safety of workers with the aim to drastically reduce accidents (De Felice, et. al. 2005). For risk analysis have been developed several techniques including: Safety Review, Checklist Analysis, Relative Ranking, What-if Analysis, Preliminary Hazard Analysis, Hazard and Operability (HAZOP), Failure Modes, Effects and Criticality Analysis (FMECA), Fault Tree Analysis (FTA), Event Tree Analysis (ETA), Cause-Consequence Analysis (CCA). In particular in our work we will focus our attention on FMECA. It should be reminded that the RPN is one form of the Failure modes, Effects and Criticality Analysis - FMECA often used in automotive or manufacturing industries. RPN uses descriptive terms to rank the probability of the occurrence $(\mathrm{O})$ of the failure, the severity $(\mathrm{S})$ of the consequence of its failure effect, and a probability of failure detection (D). RPN factors are scaled from 1 to 10 . All three factors are then multiplied to give $\mathrm{RPN}=\mathrm{S} \times \mathrm{O} \times \mathrm{D}$, result ranging from 1 (low priority) to 1000 (high priority).

The proposed methodology, namely SIRA - Safety Improve Risk Assessment presented in Figure 1, provides an estimation of the risk by defining an index called Total Risk Priority Number-TRPN.

The TRPN is based on the Improved Risk Priority Number - IRPN as proposed by Braband (2003, 2006) and the Analytic network Process - ANP, a Multi Criteria Decision Making - MCDM analysis tool. ANP, is a technique developed by Saaty with the objective to solve decisions problems (Saaty, 2005, 2006). In its general concept, the ANP (evolution of AHP model) is a nonlinear framework for carrying out inductive and deductive thinking without using syllogism by taking several factors into simultaneous consideration. The technique has found relevant application in this study. The ANP process allows us to 
extract and derive different weight according to the relative importance of the TRPN factors, in term of decision.

SIRA methodology is composed of three parts, as is show in Figure 1:

1. risk identification that is the process in which threats for the subjects of concern are investigated;

2. risk estimation that is the process in which hazard probability is evaluated;

3. risk control that is the process in which safety improvement are proposed.

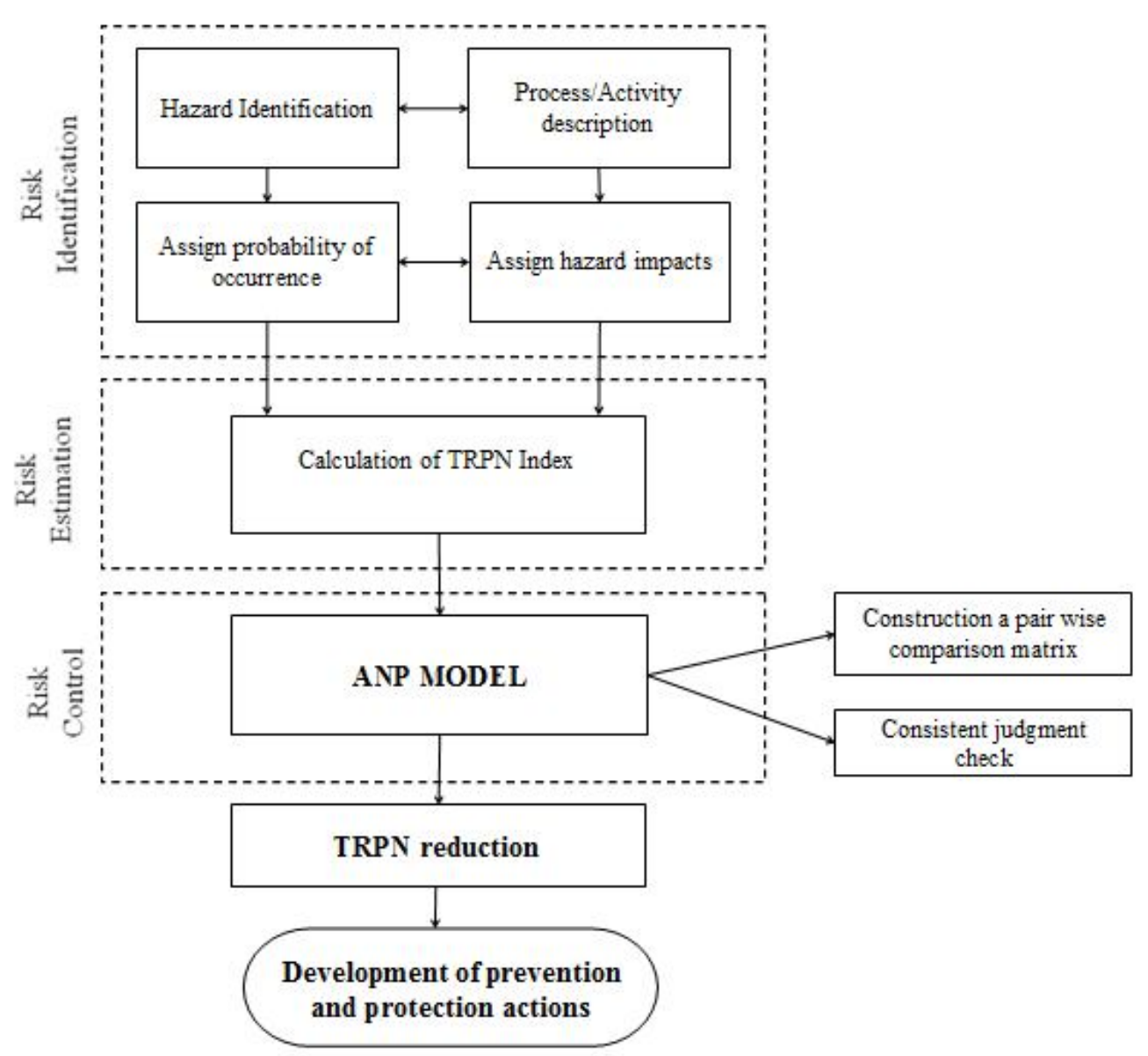

Figure 1. SIRA Methodology

\subsection{TRPN Index}

As we said above, RPN entails several problems.

The main aspect is the ranking of risks based only on few factors. In particular subsequent actions developed to reduce the highest RPN calculated before, are taken with no consideration about cost and effectiveness of actions themselves, rather than other important factors.

Starting from the evaluation of RPN for each risk, it is possible to evaluate a Total Priority Risk Number (TRPN) for the company in the present state, given by the sum of all RPN evaluated. At this point, the goal could be the reduction of TRPN, considering different criteria.

The cost-effectiveness curve shows the correlation between cost and effectiveness both of prevention and protection activities (see Figure 2). 


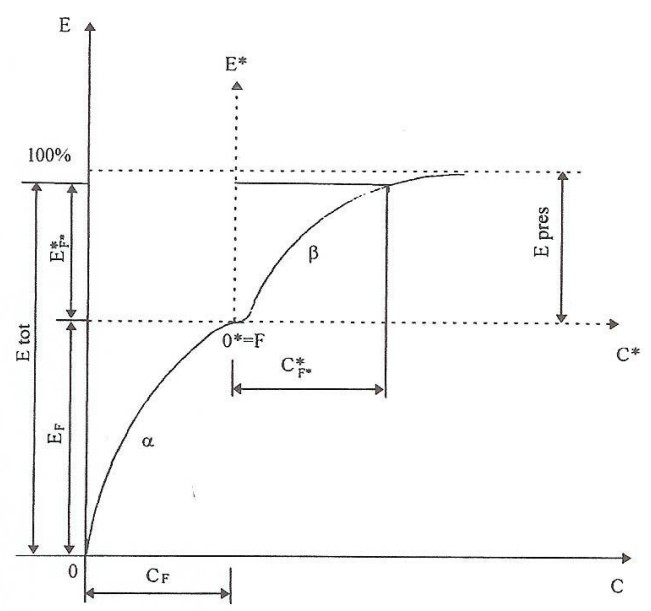

Figure 2. Cost-Effectiveness Curve

The adoption of the right interventions allows reducing one by one RPN of each risks and subsequently TRPN. The problem could be a big consumption of resources, costs and time, with a very low effectiveness in terms of reduction of TRPN. Therefore the new procedure, against FMECA approach, suggests to focus our attention on the global effectiveness, rather than major risks. The baseline idea is the identification of the best set of risks on which acting, able to realize the biggest reduction of TRPN with the lowest total cost of intervention.

\subsection{ANP Model}

At this point we defined ANP Model (Figure 3) to establish the possibility of reduction of TRPN index. To build ANP Model we formed an "expert" team work. The targeted people were OHS (Occupational Health and Safety) experts, insurances, researchers, work inspection office, safety engineers and officers.

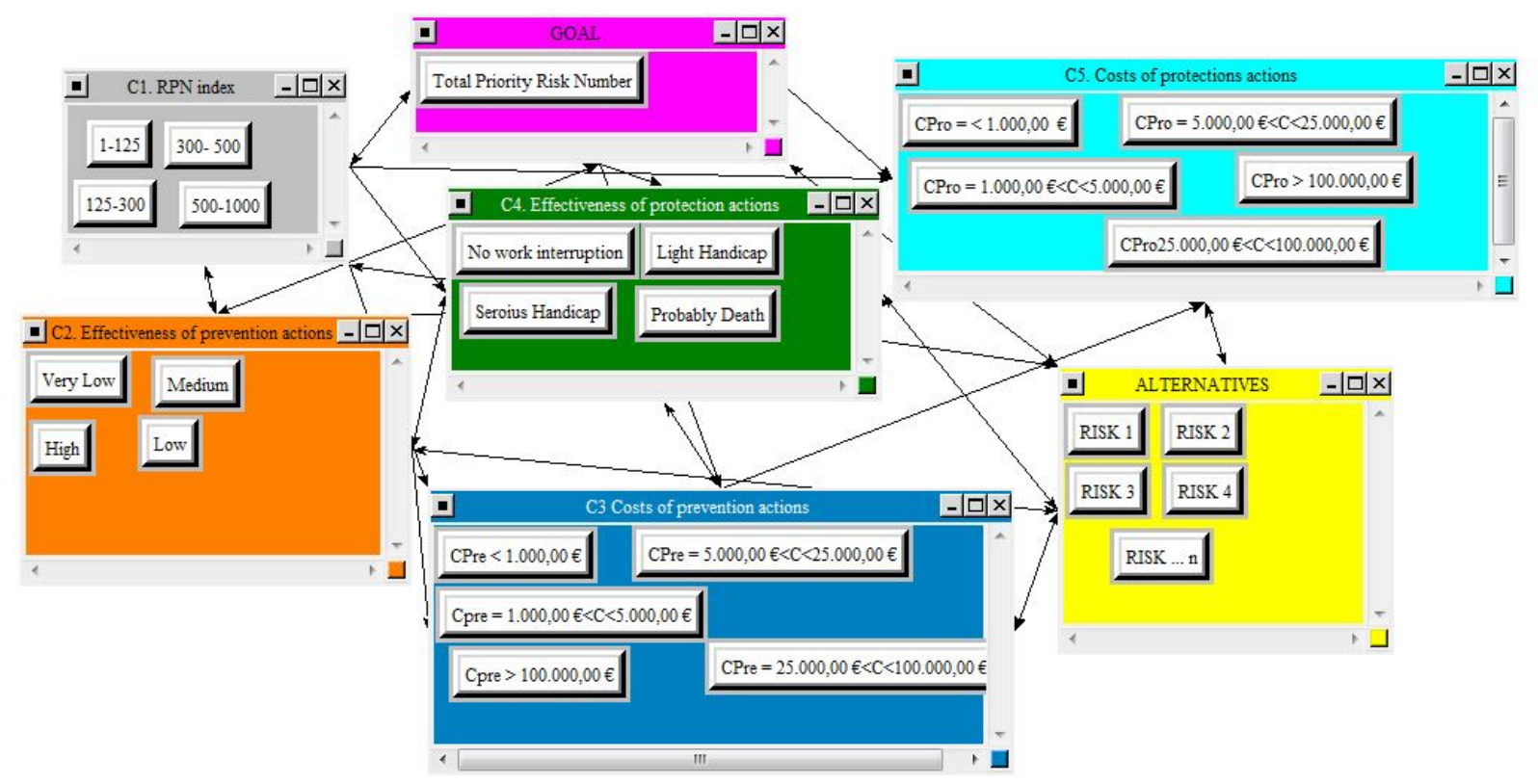

Figure 3. ANP Model 
The alternatives of the model are all risks identified in the Risk Identification step of SIRA Methodology. Instead, we have identified five criteria:

1. RPN index (previously evaluated):

2. Effectiveness of prevention actions;

3. Costs of prevention actions;

4. Effectiveness of protection actions;

5. Costs of protections actions.

In order to provide an indication of the effectiveness of corrective actions (prevention and protection) a more quantitative approach may be used. The analysis team assigns a second set of Severity, Occurrence and Detection ratings for each issue (using the same rating scales) and multiplies the revised ratings to calculate the revised RPNs. If both initial and revised RPNs have been assigned, the percent reduction in RPN can also be calculated as follows:

$$
\% \text { Reduction in } R P N=\frac{R P N_{i}-R P N_{r}}{R P N_{i}}
$$

The above percentage of reduction becomes a measure of effectiveness both of prevention and protection. For example, if the initial ratings for a potential problem are $\mathrm{S}=7, \mathrm{O}=8$ and $\mathrm{D}=5$ and the revised ratings are $\mathrm{S}=7, \mathrm{O}=6$ and $\mathrm{D}=4$, then the percent reduction in RPN from initial to revised is (280168)/280, or $40 \%$. This indicates that the organization was able to reduce the risk associated with the issue by $40 \%$ through the implementation of corrective actions (Tab. 1).

Table 1. RPN reduction and effectiveness evaluation

\begin{tabular}{|c|c|c|c|c|}
\hline & Severity & Occurrence & Detection & RPN \\
\hline Initial & 7 & 8 & 5 & 280 \\
\hline Revised & 7 & 6 & 4 & 168 \\
\hline \multicolumn{4}{|c|}{$\%$ Reduction in RPN } & $40 \%$ \\
\hline
\end{tabular}

The goal could be the reduction of many risks factors, all at once (TRPN, previously evaluated in the Risk Estimation step). The result of the ANP Model application, is a priority list different form that supplied by FMECA. Subsequently, the same actions considered by the "expert" team work during the analysis, in order to calculate costs and effectiveness of interventions, have to be implemented after, for improving safety in a workplace.

\section{Conclusions}

The fundamental objective of the proposed methodology is the support for decision-makers, in order to realize a rapid classification of analyzed risks. This consists of risks ranking and prioritizing according defined thresholds and mapping risks in four areas: acceptable, negligible, significant and considerable. The prioritization consists of the action to organize some elements, data or events in increasing or decreasing order, and by highlighting the main point of the analysis. Risk is mitigated by executing safety actions in order to decrease the probability or likelihood of occurrence (preventive action), or to reduce the consequence of an accident (protection including emergency response). The association between risk level and risk mapping on site is primordial to have a good safety management. But a good management requires also a saving of resources and a maximizing of results, which is the main aim of SIRA Methodology. Next steps in the research will deal with the validation of the method for the identification 
and prioritization of the improvement actions. It will be interesting to compare both FMECA and SIRA methods, thanks to the application to a real case study.

\section{REFERENCES}

Bowles, J.B. (2003 ). An Assessment of RPN Prioritization in a Failure Modes Effects and Criticality Analysis. Reliability and Maintainability Symposium, 380-386.

Braband, J. (2003). Improving the risk priority number concept. Journal of safety 21, 23.

Braband, J. (2006). Risk Assessment: As Simple as Possible (and No Simple). In: CNF, I. (Ed.), System Safety, 2006. The $1^{\text {st }}$ Institution of Engineering and Technology International Conference pp. 285-299.

Silvestri A., De Felice F., Falcone D., Di Bona G. (2004). R.A.M.S. Analysis in a sintering plant by the employment of a new Reliability Allocation Method Modelling and Simulation 2004 Marina del Rey, CA, USA.

De Felice F., Falcone D., Silvestri A., Petrillo L. (2005). Proposal of a New Decision Making multi criteria Methodology applied to the reengineering of layout in an electromechanical company: the Score Analytic Hierarchy Process, $18^{\text {th }}$ International Conference on Production research, Salerno (Italy).

La Tegola O., Verrecchia G. (2009). Le novità del Testo unico in tema di sicurezza sui cantieri temporanei e mobili, in Quaderni Olympus On Line www.uniurb.it/olympus/index 2 .php?option=com content\&do $\mathrm{pdf}=1 \& \mathrm{id}=1836$.

L. Montuschi, (1991). La tutela della salute e la normativa comunitaria: l'esperienza italiana, in AA.VV., Tutela dell'ambiente di lavoro e direttive CEE, M. Biagi ed., Rimini, 18.

Pascucci P., Dopo la legge n. 123 del 2007. Titolo I del d. lgs. 9 aprile 2008, n. 81 in materia di tutela della salute e della sicurezza nei luoghi di lavoro, in WP C.S.D.L.E. "Massimo D'Antona". IT - 73/2008, p. 122.

Ricci M. (1999). Alcune osservazioni introduttive in tema di sicurezza sul lavoro, in M. Ricci (ed.), La sicurezza sul lavoro. Evoluzione legislativa, esperienze applicative e prospettive di riforma, Cacucci, p. 17 ss.

Saaty, T.L. (2005). Theory and Applications of the Analytic Network Process: decision making with benefits, opportunities, costs, and risks, Ed. RWS Publications.

Saaty T. L. (2000). The Analytic Hierarchy Process, McGraw-Hill. 